\title{
Effects of high-volume hemofiltration on lung oxygenation in patients with septic shock
}

\author{
EA Tishkov ${ }^{*}$, AN Kuzovlev² $^{2}$ OB Bukaev ${ }^{3}$, Y Luzganov $^{2}$ \\ From ESICM LIVES 2015 \\ Berlin, Germany. 3-7 October 2015
}

\section{Introduction}

High-volume hemofiltration (HVHF) is technically possible in severe acute disease abdominal cavity patients complicated with multiple organ dysfunction syndrome (MODS). Continuous HVHF is expected to become a beneficial adjunct therapy for acute pancreatitis and peritonitis complicated with MODS. In this study, we aimed to explore the effects of fluid resuscitation and HVHF on alveolar-arterial oxygen exchange, the Acute Physiology and Chronic Health Evaluation II (APACHE II) score in patients with septic shock.

\section{Objectives}

This study was undertaken to explore the effects of fluid resuscitation and HVHF on alveolar-arterial oxygen exchange, APACHE II score in patients with septic shock.

\section{Methods}

A total of 45 septic shock patients, who were admitted to ICU, were enrolled in this retrospective study. The patients were randomly divided into two groups: fluid resuscitation (group $\mathrm{A}, \mathrm{n}=20$ ), and fluid resuscitation plus high-volume hemofiltration (group $B, n=25$ ). The levels of $\mathrm{O} 2$ content of central venous blood ( $\mathrm{CvO} 2)$, arterial oxygen content $(\mathrm{CaO} 2)$, alveolar-arterial oxygen pressure difference $\mathrm{P}(\mathrm{A}-\mathrm{a}) \mathrm{DO}$, ratio of arterial oxygen pressure/alveolar oxygen pressure $(\mathrm{PaO} 2 / \mathrm{PAO} 2)$, respiratory index and oxygenation index were determined. The oxygen exchange levels of the two groups were examined based on the arterial blood gas analysis at different times $(0,24,48$ hours and 5 days of treatment) in the two groups. The APACHE II score was calculated before and after 5-day treatment in the two groups.

Moscow University of Medicine and Dentistry, Dept. of Anesthesiology and Reanimatology, Moscow, Russian Federation

Full list of author information is available at the end of the article

\section{Results}

The levels of $\mathrm{CvO} 2, \mathrm{CaO} 2$ on day 5 in group A were significantly lower than those in group $\mathrm{B}(\mathrm{CvO} 2: 0.62 \pm 0.22$ vs. $0.74 \pm 0.24, \mathrm{P}<0.05 ; \mathrm{CaO} 2: 0.82 \pm 0.36$ vs. $0.95 \pm 0.42$, $\mathrm{P}<0.05)$. The level of oxygen extraction rate $(\mathrm{O} 2 \mathrm{ER})$ in group $\mathrm{A}$ on the 5 th day was significantly higher than that in group $\mathrm{B}(29.7 \pm 2.5$ vs. $22.7 \pm 3.5, \mathrm{P}<0.01)$. The levels of $\mathrm{P}(\mathrm{A}-\mathrm{a}) \mathrm{DO} 2$ and respiratory index in group $\mathrm{B}$ on the 5 th day were significantly lower than those in group $\mathrm{A}$. The levels of $\mathrm{PaO} 2 / \mathrm{PAO} 2$ and oxygenation index in group $\mathrm{B}$ on 5th day were significantly higher than those in group A $(\mathrm{P}<0.05$ or $\mathrm{P}<0.01)$. The APACHE II score in the two groups reduced gradually after 5 -day treatment, and the APACHE II score on the 5th day in group B was significantly lower than that in group A $(8.0 \pm 2.8$ vs. $18.2 \pm 5.8$, $\mathrm{P}<0.01)$.

\section{Conclusions}

HVHF combined with fluid resuscitation can improve alveolar-arterial-oxygen exchange, decrease the APACHE II score in patients with septic shock, and thus it increases the survival rate of patients.

\section{Authors' details}

${ }^{1}$ Moscow University of Medicine and Dentistry, Dept. of Anesthesiology and Reanimatology, Moscow, Russian Federation. ${ }^{2}$ V.A. Negovsky Research Institute of General Reanimatology, Moscow, Russian Federation. ${ }^{3}$ Moscow City Hospital \#1, Moscow, Russian Federation.

Published: 1 October 2015

\section{doi:10.1186/2197-425X-3-S1-A58}

Cite this article as: Tishkov et al:: Effects of high-volume hemofiltration on lung oxygenation in patients with septic shock. Intensive Care Medicine Experimental 2015 3(Suppl 1):A58.

\section{SpringerOpen ${ }^{\circ}$}

(c) 2015 Tishkov et al.; This is an Open Access article distributed under the terms of the Creative Commons Attribution License (http:// creativecommons.org/licenses/by/4.0), which permits unrestricted use, distribution, and reproduction in any medium, provided the original work is properly cited. 